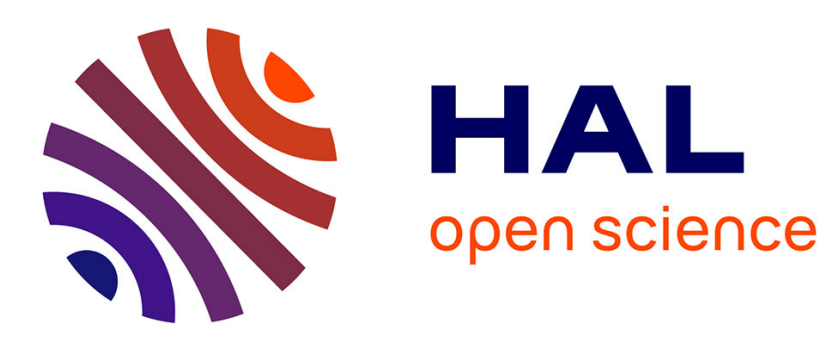

\title{
The prevention of slipping accidents: a review and discussion of work related to the methodology of measuring slip resistance
}

Sylvie Leclercq

\section{> To cite this version:}

Sylvie Leclercq. The prevention of slipping accidents: a review and discussion of work related to the methodology of measuring slip resistance. Safety Science, 1999, 31 (2), pp.95-125. 10.1016/S09257535(98)00064-2 . hal-01578589

\author{
HAL Id: hal-01578589 \\ https://hal.science/hal-01578589
}

Submitted on 29 Aug 2017

HAL is a multi-disciplinary open access archive for the deposit and dissemination of scientific research documents, whether they are published or not. The documents may come from teaching and research institutions in France or abroad, or from public or private research centers.
L'archive ouverte pluridisciplinaire HAL, est destinée au dépôt et à la diffusion de documents scientifiques de niveau recherche, publiés ou non, émanant des établissements d'enseignement et de recherche français ou étrangers, des laboratoires publics ou privés. 
CORRESPONDING AUTHOR :

Sylvie Leclercq

French National Research and safety Institut (INRS)

Ergonomy and Industrial Psychology department

Avenue de Bourgogne - BP 27

54501 Vandoeuvre Cedex - FRANCE

Tel : :33 383502000

Fax $\quad: 33383502182$

e-mail : leclercq@inrs.fr 
THE PREVENTION OF SLIPPING ACCIDENTS : A REVIEW AND DISCUSSION OF WORK RELATED TO THE METHODOLOGY OF MEASURING SLIP RESISTANCE

\author{
S. LECLERCQ \\ French National Research and Safety Institut (INRS) \\ Ergonomics and Industrial Psychology department \\ 54500 Vandoeuvre - FRANCE
}

Accepted for publication in Safety Science 


\section{ABSTRACT}

The recommendations made after the analysis of accidents following an incident of slipping often include the use of anti-slip footwear and/or the installation of an anti-slip floor covering. Such recommendations make it necessary to study biomechanical and tribologic phenomena that occur during slipping, in particular in order to develop criteria for the evaluation of the slip resistance of footwear and floor surfaces. Consequently, research which deals with the prevention of slipping is more or less directly related to the methodology of measuring slip resistance, and can have many objectives, including :

- the study of the conditions or accident-related factors encountered at the time of slipping in an industrial context,

- the analysis of the dynamic of slipping at the interface between a slippery floor and the foot,

- the analysis of tribologic phenomena that occur at this interface,

- the choice of a relevant criterion to assess the slip resistance or

- the development of a test bench.

The results of these studies can be used to express preventative recommendations or to support/discuss standardisation projects on the measurement of the slip resistance of protective shoes or floor coverings. Globally speaking, these studies have contributed to a better understanding of the complexity of slips and of their prevention, and it is for this reason that they are reviewed in the current paper. Special emphasis will be placed on the differences observed between the different approaches rather than on the multitude of (occasionally contradictory) results obtained from them. This literature review has allowed us to partially explain the reasons that slow down progress in harmonising methods for the measurement of slip resistance, and also to explain the more recent studies on perturbed locomotion or posture. 
These studies have been undertaken on the strategies used to confront the risk of falling or to cope with the loss of balance.

\section{INTRODUCTION}

The prevention of slips represents a significant portion of the studies and research carried out on same level falls. In effect, slipping contributes to approximately $12 \%$ of all occupational accidents (Strandberg and Lanshammar, 1981). Also, the recommendations made after the analysis of accidents following an incident of slipping often include the use of anti-slip footwear and/or the installation of an anti-slip floor covering. Such recommendations make it necessary to study biomechanical and tribologic phenomena that occur during slipping, in particular in order to develop criteria for the evaluation of the slip resistance of footwear and floor surfaces.

Once they were developed, methods for the measurement of slip resistance were used for different purposes. First of all, they have been used to compare products (footwear or surfaces) in existing markets, and to set up lists of recommended products. In this case, the slip resistance of footwear is assessed with respect to a slippery reference surface (usually covered with a reference lubricant), and the slip resistance of different surfaces is assessed with respect to a given shoe, or model of shoe, and a reference lubricant. With this type of arrangement it is possible to study the characteristics of the sole of the shoe (relief, material) or of the floor surface (roughness, permeability...) that improve slip resistance.

In general, this type of study is performed in the laboratory on new products. However, the properties of floor surfaces and footwear are constantly modified as a function of wear, dirt, and humidity. While it is possible to test the slip resistance of used footwear in the laboratory, the same cannot be said for worn 
surfaces. In this case it is necessary to have access to a portable device in order to be able to assess slip resistance in situ at industrial sites (surfaces that are more or less worn, more or less soiled). Such measurements can also be used to test the effect of specific factors that are linked to use : factors such as the type of soil, cleaning, wear, etc. .

The current work provides a review of the work dealing with the methodology of measuring slip resistance. Most of this work deals with occupational accidents or prevention. Special emphasis will be placed on the differences observed between the different approaches rather than on the multitude of (occasionally contradictory) results obtained from them.

\section{SITUATION STUDIED : TERMINOLOGY}

Information available from literature and national statistics is essentially incomparable and is therefore difficult to synthesize (Leclercq, 1998a). Most of it is dealing with same level accidents, but not with slipping accidents (a subset of same level accidents for which the loss of balance is caused by slipping). The study carried out by Strandberg and Lanshammar in 1981 concerned about 83000 occupational accidents including about 10000 accidents during which "slipping" was a contributory factor. This is the reason why it is so often referred to.

Statistical studies of slipping in accidents show that :

- the victim is walking normally at the time of the accident in $59 \%$ of the cases (Strandberg and Lanshammar, 1981).

- in all sectors of activity together, approximately one out of two such accidents occurs indoors (Strandberg and Lanshammar, 1981 ; Tissot, 1994). 
- the ground covering is soiled in approximately $80 \%$ of the cases (Manning et al., 1988 ; Gronqvist and Roine, 1993), being covered with liquids in $45 \%$ of the cases (Manning et al., 1988), by ice or snow in $15 \%$ (Strandberg and Lanshammar, 1981 ; Manning et al., 1988), or strewn with objects in $21 \%$ of the cases (Manning et al., 1988).

It is for these reasons that the case studies examined are slips that occured on hard, soiled floor surfaces (covered by a more or less viscous product) or on ice, with a subject who walks and slips while wearing either street or safety footwear (boots or shoes). This situation reflects the more dangerous conditions ( Strandberg, 1985 ; Tisserand, 1985 ; Gronqvist, 1995a), but as indicated by Skiba (1985), it is not representative of all types of slipping. If we consider the information cited above, along with the fact that slipping contributes to approximately $12 \%$ of occupational accidents (Strandberg and Lanshammar, 1981), it can be supposed that this situation is representative of somewhere between 4 to $7 \%$ of occupational accidents.

The forces found at the shoe/surface interface at a given time $t$ are represented in Figure 1. The ratio $\mathrm{T} / \mathrm{N}(\mathrm{t})$ is the friction required index (as defined by Rhoades and Miller, 1988), and depends in particular on the task at hand. The ratio $T^{\prime} / N^{\prime}(t)$ is the friction use index (as defined by Strandberg, 1985). Its value is a function of the friction required and the friction available $\left(\operatorname{Tmax} / \mathrm{N}^{\prime}(\mathrm{t})\right)$ which itself depends on tribologic conditions (state of surface, extent to which it is soiled,...). The available friction index is the maximum possible value that the ratio $T^{\prime} / N^{\prime}$ can have at a given instant. If the required friction is greater than the available friction, the sole will slip on the surface, and the used friction is assimilated with the available friction during the slip. The friction index $T^{\prime} / N^{\prime}(t)$, which is proportional to the force opposing (resisting) the slipping motion, is commonly referred to as the slip resistance or skid resistance. The slip resistance offered by a shoe or a floor coating can be assessed by means of a mechanical device, either directly or indirectly, with a 
criterion which can vary inversely with the friction (e.g. the stopping distance, or the distance necessary for an object that has been pushed by an impulse into a slipping motion over a surface to come to a halt). Here, one tends to speak in terms of slipperiness. The terms slipperiness, slip resistance, and anti-slip are sometimes used interchangeably. The threshold (or adequate slip resistance) is the limiting value, beyond which the risk of falling after slipping is considered to be negligible.

In order to be able to make a distinction between anti-slip products and those that are not slip resistant in terms of footwear or floor coatings, it is necessary to precisely define the conditions under which the slip resistance is measured (movement between the elastomer and the surface, the normal force, sliding speed...), and a safety threshold value. The different studies carried out in this area have produced a multiplicity of measurement methods and apparatus, certain principles of which are still being debated.

\section{METHOD DEVELOPED AT THE INRS FOR THE EVALUATION OF SLIP RESISTANCE}

The INRS began to propose the use of a test bench and method for the evaluation of the slip resistance of safety shoes in 1969 (Tisserand, 1969). This method was previously described by Tisserand (1985). The principle test conditions are represented in Figure 2 and include : the shoe is posed flat on a sheet of stainless steel covered with oil, a vertical force of 600 Newtons maintains the shoe against the surface, and at the moment the measurement is made, the relative velocity between the oiled surface and the shoe is $0.2 \mathrm{~m} / \mathrm{s}$. The measurement conditions were defined so that the measured index reflects as much as possible the impression of safety felt by subjects wearing different test shoes, and sliding over an oiled sheet of stainless steel. A simplified model 
of slipping was used to express the requirements in terms of static friction (measured at the instant that the relative shoe-surface movement begins) and dynamic friction (measured during the slipping of the shoe on the surface) :

- prevent the initial slipping of the foot : high static friction,

- limit the acceleration of the slipping motion in order to reduce any perturbation of the subject's balance : i.e. a slight difference between the static and dynamic friction if one accepts the hypothesis that the static friction force is higher than the dynamic friction force.

The sensations felt by the subjects showed that the static friction index was inversely correlated with the impression of safety, and that the dynamic friction index and the difference between the two indices reflected the feeling of safety. This was the first time that the relevance of the measurement of a dynamic friction index was demonstrated in terms of safety as it relates to slipping. Later studies on the dynamics of the forces at the slip-surface/shoe interface confirmed the relevance of the choice of a dynamic friction index, and allowed people to deepen their knowledge of the slip-related phenomena.

\section{INTERLABORATORY COMPARISON}

Similar developments took place outside of France. Numerous methods and devices were developed. However, it was only at the beginning of the 1980s that this work was widely published in international scientific reviews. At this time, Strandberg (NBOSH, Sweden) was directing an ambitious project that brought together most of the specialists in the area of the prevention of slipping. This project provided one of the first occasions for inter-laboratory tests. It represents a turning point, and is still considered as a reference in the domain. 


\subsection{DEVICES EVALUATED}

In limiting himself to developments concerning the safety of pedestrians, Strandberg (1983a) found in the literature 92 methods for the measurement of slip resistance using 62 distinct devices (different methods being possible with a given device). There was a wide variety of measurement principles, as well as of types of information output. It is not particularly useful to list them all here (see, e.g. Strandberg, 1983a). 25 different methods were compared during this inter-laboratory test, and each of the methods was applied to 13 combinations of surface/lubricant/sole (Strandberg, 1985).

\subsection{OBJECTIVES}

Two criteria for determining the acceptability of a method were proposed :

- its reproducibility, which was assessed in terms of the dispersion of the measurements obtained using a given method when the measurement conditions do not vary.

- its validity. Strandberg and Lanshammar (1981) listed the essential variables that should be reproduced by the measurement devices in order to assure the validity of the method. These included : the angle that the foot makes with the ground, as well as the point of application of the contact force in order to test the most important part of the shoe; the vertical force in order to respect the pressure in the contact zone; the time scale in order to be able to account for the possibility of drainage from the relief on the sole; and finally, the sliding speed. If the values of these biomechanical parameters are sufficiently realistic, then the complex tribological phenomena produced during the slipping action will also be realistic. 


\subsection{IDENTIFICATION OF VALUES OF THE ESSENTIAL PARAMETERS}

In order to identify the values that should be attributed to these parameters with the objective of developing a valid model of slipping, Strandberg and Lanshammar (1981) positioned subjects in a situation likely to provoke a loss of balance due to slipping. They studied in detail the tribological phenomena occuring at the surface/shoe interface when a subject encounters a polluted surface whilst walking normally. Their work confirms the results obtained by Perkins (1978) - the detailed results of these two studies are mentioned below . In particular, it was emphazised that the most critical phase of equilibrium for a subject walking normally in a straight line is the moment of impact of the heel with the surface. They provide an image of the surfaces in contact, and of the dynamics of the forces at the interface at this time. The results of their experiments also confirmed that a dynamic friction index is a relevant means of representing safety with respect to slipping. Effectively, the authors noted a slipping of the heel at the moment of contact for most of the trajectories. This movement was generally not noticed by the subject, and even occured when no lubricant was present on the surface.

Perkins (1978) analysed both the horizontal and vertical components of the force exerted between the shoe and the ground during normal walking, as well as films retracing slips. He arrived at the following conclusions :

- during a normal gait, a fall can result when the foot slides forward at the moment that the heel comes into contact with the surface. At this instant the average value of the ratio of the horizontal force/vertical force is approximately 0.2 for 8 subjects, and the maximum values were approximately 0.33 and 0.26 ( 2 successive peaks on the curve). 
- if the length of the slip exceeds 10 to 15 centimetres, a loss of balance occurs.

- in certain cases the subject regained balance after slipping a short distance. This was explained by the fact that the entire shoe rapidly comes into contact with the surface after the onset of the slip, and thus increases the level of friction.

Strandberg and Lanshammar (1981) placed 4 subjects in a harness and had them walk in a straight line, or slip on a flat, level surface covered occasionally with some sort of pollutant. They made a certain number of observations based on 124 experiments :

- a slipping of the heel on the surface at the moment of contact was observed during most of the tests. This movement is generally not noticed by the subject, and occurs even if there is no lubricant on the surface.

- on average, the critical slipping movement occurs 0.05 seconds after the heel touches down. At this instant, the vertical force is equivalent to approximately $60 \%$ of the body weight If is applied between the heel of the sole - which makes an angle of approximately $5^{\circ}$ with the surface - and the surface.

- once initiated, a slip will progress if the horizontal force/vertical force ratio continues to increase after it begins.

- when the slip speed exceeds $0.5 \mathrm{~m} / \mathrm{s}$, or when the length of the slip exceeds $0.1 \mathrm{~m}$, the slip generally leads to a fall.

- when there is no dangerous slip, the maximum value of the horizontal force/vertical force ratio at the beginning of the rolling action of the foot, was, on average, equal to 0.17 and was detected $90 \mathrm{~ms}$ after the contact of the heel.

- when a slip does not lead to a fall, the horizontal force/vertical force ratio varies between 0.1 and 0.2 during the time that the foot slides forward.

- sliding movements to the rear that occur just before the toes are lifted from the surface never led to a loss of balance, nor to a fall. 
The calculation of the large number of parameters required a sophisticated experimental set-up, and limited the collection of information to the duration of one pace taken at a normal walking rhythm. As pointed out by Strandberg (1985), it is not possible to explore the entire course of an accelerating or decelerating subject, nor a subject walking normally around a corner in the same way. Furthermore, the observed levels of inter and intra-subject dispersion in the measured parameters led Strandberg and Lanshammar (1981) to only take the order of magnitude of the numerical values into consideration.

\subsection{CONCLUSION}

The wide variability of the biomechanical quantities prevents one from defining precise values for the parameters defined by Strandberg and Lanshammar (1981) as being essential for the evaluation of slip resistance at the instant of impact of the heel on the ground - the critical phase for maintenance of balance while walking normally in a straight line -. Furthermore, the experimental conditions also limited the gathering of information to the duration of one pace of a normal walk. It was therefore not possible to do as foreseen and draw any conclusions on the validity of the 25 measurement techniques to be compared only on the basis of these measurements. It is for this reason that Lanshammar and Strandberg (1985) developed a reference method that did take into account variations in the slip resistance for different types of gait, accelerations, decelerations, as well as conditions specific to walking through curves. This method, that they qualified as "psycho-physical" is based on measurements of the subject's performance over a closed triangular path where they are asked to walk as rapidly as possible without falling. In this manner they are supposed to use the entirety of the available friction. The time required to complete the path is used in a mathematical model to estimate the available friction for the slippery 
surface/shoe tested. If the results of a method of measurement are correlated with the measurements obtained with the reference method, then this first method can be considered to be valid. The validity of several different measurement techniques was demonstrated, even though certain parameters used in calculating the friction index were not really "realistic" - i.e. they didn't represent the dynamics of the forces at the moment of impact of the heel just before the beginning of the slide -.

So we can ask ourselves : "Is it really necessary that the measurement equipment precisely reproduce the dynamics of this impact, or is it sufficient that the validity of the methods are demonstrated by a comparison with a more global reference method?"

This international project allowed us to appreciate the requirements that are important to a methodology for the evaluation of the slip resistance of a slippery surface/shoe, and suggests the difficulty that those involved in accident prevention will have in finding a consensus in the matter - a difficulty that increases with the ever-increasing number of methods and devices. A review of the works and opinions that seem to be essential (at least to the author of the current work) are discussed in the following sections.

\section{DYNAMICS OF THE FORCES AT THE SLIPPERY SURFACE/SHOE} INTERFACE

\subsection{THE HORIZONTAL DRIVING FORCE}

When Perkins (1978) and Strandberg and Lanshammar (1981) studied slipping that occurred during a normal, rectilinear walk, they neglected the component of the horizontal force perpendicular to the direction of walking (the medio- 
lateral component). Several authors have shown that this component is not always negligible :

- In 1982, Bring did so but underlined the fact that the cases encountered could nevertheless be exceptions given the unanimity of acceptance of the very low amplitude of the lateral component (a fall due to slipping is also an exception, is it not ?). Nevertheless, Bring (1982) never observed a slipping direction that deviated significantly (more than $3^{\circ}$ ) from the direction of walking during (normal) walking over a slippery surface. According to him, this lateral component can, in certain cases, lead to a ratio of horizontal force/vertical force greater than the friction index, and therefore to slipping.

- Leamon (1988) established the importance of the medio-lateral component of the driving force at the moment of the contact of the heel during the measurements of the sliding distance in this plane.

- Gronqvist (1989) observed that when the foot begins to slide after the impact of the heel, the horizontal force is not purely in the direction front-to-back. It seems likely that the foot slips both forward and sideways. In effect, the first point of contact at the moment of impact of the heel is normally the exterior side of the back of the heel.

- Skiba et al. (1983) observed that the shoe makes an angle of $9^{\circ}$ in the direction of walking at the instant of impact of the heel.

\subsection{VARIABILITY OF THE FORCE DYNAMICS}

Like Strandberg and Lanshammar (1981), Brough et al. (1979), Soames et Richardson (1985), Hoang et al. (1987) as well as Gronqvist et al. (1993) pointed out that they observed significant intra-individual and inter-individual variability of the dynamics of forces, specially at the heel strike. Hoang et al. (1987) observed significant levels of inter-individual variability, and an intraindividual variability that depended on walking speed. Soames and Richardson 
(1985) found that the cadence had a stronger influence on the peaks of the components of the reaction force (shoe/ground) than did the length of the step. The fact that this wide dispersion of parameter values was noted in the context of precise experiments suggests that the dispersion of these same parameters would be even greater if they were estimated in the wide diversity of industrial situations that can be encountered.

\subsection{ACTIVITY OF THE SUBJECT}

Slips and falls can also occur when a subject is pushing or pulling a load, or, more generally, when he is trying to perform a task that requires high levels of shear stress at the foot/ground interface. It is for this reason that Redfern and Andres (1984) studied a friction index (slip resistance) required for these tasks. They demonstrated that a friction index was at a maximum when the load and pushing speed were maximal (and vice versa). The height of the hands and the direction of the force (pushing or pulling) had no influence at all.

Perkins (1978) and Strandberg and Lanshammar (1981) demonstrated that a slipping distance greater than $10 \mathrm{~cm}$ at the moment of impact of the heel leads inevitably to a fall. It is for this reason that Leamon (1988) chose the slipping distance at the moment of impact as an indicator of the risk of falling during a study of walking while carrying a load. It was concluded that, when carrying a load, the subjects decreased the length of their steps with respect to this same parameter with no load, regardless of the weight of the load and the walking speed. The slipping distance increased as the walking speed increased.

Bönig (1996) showed that the friction used increased as a function of the walking speed, but did not depend on whether or not the subject was carrying a load. 
After confirming the order of magnitude of the parameters measured by Strandberg (1983b), Redfern et al. (1991), observed that carrying a load had very little effect on the impact of the heel during walking.

Bloswick and Love (1991) defined the tendency to slip as the maximum value of the ratio of the lateral and normal forces exerted on the ground during the 25 ms following the impact of the heel. They studied this tendency for cases where a load was being carried as a function of walking speed and manner of carrying the load. This index increased by a factor of $27 \%$ on average for a rapid speed with respect to the slower speed. With respect to the case where no load was carried, the tendency to slip decreased when the load was carried in front of the body, and increased when the load was carried to one side.

\section{CHOICE OF A RELEVANT CRITERION}

Beginning with the hypothesis that there is no relative motion between the foot and the ground during the support phase of a normal walk, the initial work done by people involved in the prevention often dealt with the measurement of a static friction index measured at the moment the movement between the surface and the shoe began (e.g. Ekkebus and Killey, 1973). In effect, maximising an index of static friction in this case is the same thing as minimising the probability of initiating a slip, but in the event that slipping does occur, this presents no guarantee that a fall would be prevented. Tisserand (1969) added a requirement : limit the acceleration of the slipping motion in order to reduce any perturbation of the subject's balance. This is reflected by a very slight difference between static and dynamic friction indices if we accept the hypothesis that a static friction force is greater than a dynamic friction force. Strandberg and Lanshammar (1981) demonstrated that, even on dry surfaces, the shoe slides over the surface at the instant of impact of the heel. In 
this case, in order to prevent slipping, it would make no sense to maximise a static friction index, and the second requirement would then no longer be translated in terms of the difference between static and dynamic friction, but rather in terms of the gradient of dynamic friction at the onset of the slip. It is for this reason that Stevenson (1992) wrote that "a single measurement recorded in realistic conditions is a good indicator of the slip resistance, even if a measurement of the variation of a dynamic friction index is better because a friction index that increases as a function of speed could stop an on-coming slip." Perkins and Wilson (1983) performed the same analysis, and wrote that two measurements are necessary, one at low speed, and one at a higher speed. For approximately 15 years now, authors have been expressing their preference for the measurement of one or two values of a dynamic friction index (cf. Skiba et al., 1987 who cite these authors, and James, 1983). According to Hoang et al. (1987), these measurements represent the most realistic manner of representing a slip on a soiled surface. Skiba (1986) and Gronqvist (1995a) point out that measuring the instantaneous value of a friction index is more appropriate than the measurement of an integrated value.

An index of static friction has been commonly measured in the U.S.A. for a long time. As early as 1972, the Americans Williams et al. questioned the choice of this index and observed that these measurements do not really reflect an impression of safety. At the time of writing, some authors have suggested that the situation studied should be less restrictive, i.e. should take dry floor surfaces into consideration. Myung et al. (1992) showed that measurements of both dynamic and static friction are relevant on dry surfaces. Chaffin et al. (1992) showed that, under dry conditions, an index of static friction is a more realistic indicator of slipping than on soiled surfaces, where an index of dynamic friction is preferable.

As underlined in this chapter, the choice of a relevant criterion has been widely discussed and is still debated. Actually, a relevant criterion is a valid criterion 
and this debate could come to an end as soon as a consensus on the validity of the measurement methods has been found.

\section{DEVELOPMENT OF DEVICES - COMPARISON OF METHODS}

- since the mid-1980s, new measurement devices have been developed (e.g. Gronqvist (1989) ; Stevenson et al. (1989) ; Manning et al. (1990) ; Wilson (1991)) and numerous studies have been performed on the sensitivity of the measurement of slip resistance obtained with a given device with respect to variations in the parameters of the measurement. For example, Tisserand (1985) presented the influence of the slip speed and apparent contact pressure on the measurement of a dynamic friction index. Redfern and Bidanda (1994) studied the effects of variations in the slip speed, apparent contact pressure, shoe/ground contact angle, type of surface, type of contaminant, and sole material on the measured value of a dynamic friction index. These studies revealed the parameters to which the measurements are most sensitive. If these parameters are those included in the method (slip speed, pressure, etc.), the results can be used to improve the reproducibility of the measurement. If these parameters depend on the product to be tested (e.g. the material from which the sole of the shoe is made) the results can be used to set out certain recommendations in the area of prevention.

- other studies have compared different measurement methods. For example :

- As early as 1964 , Bring proposed a typology of devices for the measurement of slip resistance, and discussed their principles with respect to the dynamics of slipping studied in the laboratory.

- More recently, Andres et Chaffin (1985) compared 6 measurement devices. The comparison was based on 4 criteria : relative coherence of 
the devices, the repeatability of the measurements, ease of use and exactitude.

- Skiba (1984) proposed a grid for the comparison of 9 devices based on 14 criteria : the possible replacement of the samples (shoes, surfaces), use of an entire shoe, the possibility of adjusting the angle between the shoe and the surface, the variability of the vertical force during the test, the possibility of measuring the initial value of the friction index, the possibility of measuring friction indices for speeds of up to $0.5 \mathrm{~m} / \mathrm{s}$, whether or not the sample remains on the surface for less than 1 second, simulation of a walking action, the possibility of introducing lubricants, ease of handling, portability, and possibility of the standardisation of the device, constancy of the results, and its price.

- Jung and Schenk (1990), and Jung and Fisher (1993a ; 1993b) analysed the measurement of the slip resistance of 9 types of safety shoe using 10 different methods used in 7 countries. They analysed the correlation between the different series of measurements as a function of the type of floor surface and the type of lubricant used for the measurement, the correspondence between the numerical values, the repeatability, reproducibility, and validity of the measurements.

- Skiba et al. (1994) compared the repeatability, the reproducibility and validity of 6 devices for the measurement of the slip resistance of surfaces.

- Tisserand et al. (1997) compared 7 methods of measuring the slip resistance of floor surfaces, methods used in France. This included an analysis of the use of the device, its repeatability, discriminating power, validity of the measurements, and the correlation between the different series of measurements.

It is not useful to review in detail, in the current work, all of the results and technical discussions relating to measurement devices, and to comparison of 
different methods. It is clear that many different criteria are used in the comparisons, and that they are not all of the same order. They deal with :

- the principle and parameters of the measurement,

- the use of the method,

- the quality of the measurements,

- the agreement of the measurements amongst themselves

Above all, the criteria essential to determine whether to maintain or abandon a method remain those defined by Strandberg (1985), i.e. the reproducibility and validity of the measurements.

\subsection{REPRODUCIBILITY}

Reproducibility is a well-defined quantity that has been standardised (NF ISO $5725,1987)$, and measures the maximal variability of the results obtained from tests performed in very different conditions : in different laboratories, with different operators, and on different equipment. Despite this, there are still problems of reproducibility in the area of the measurement of slip resistance. In effect, the prevention of slipping requires that one consider risky situations, which are essentially situations where there is very little friction between the shoe and the floor surface. In this sense, we are therefore interested in a narrow range of slip resistance measurements. Furthermore, friction is very sensitive to the state of the surfaces that are in contact (roughness, porosity, surface energy), to any intermediate product that might be present between the surface and the shoe (amount, viscosity), and to the movement of the shoe on the surface (vertical force, slip speed, dynamics of the movement, configuration of the shoe relative to the surface).

In order to obtain reproducible measurements, it is necessary to precisely identify all of the parameter values to which the measurement is sensitive. These parameters can vary from one measurement method to the next, and 
from one apparatus to the next. For example, Gronqvist and Hirvonen (1995) observed that it was very difficult to obtain reproducible measurements of the slip resistance of shoes on ice because it was difficult to control the properties of the ice (temperature, structure, hardness, thickness of water layer). However, it was possible to obtain a good level of reproducibility of the measurement of the slip resistance of shoes on oiled stainless steel using the same given device if the shoe/surface angle was not varied during the measurements (Gronqvist, 1989).

Jung and Fisher (1993b) analysed the measurement of the slip resistance of shoes as carried out in conformity with international proposals (ISO Projects) from eight different laboratories. They concluded that, given the poor level of reproducibility (they obtained) :

- either the devices did not operate as claimed in the proposals,

- or these proposals neglected to set the values of some essential parameters, - or the parameter values were not defined precisely enough.

Also, the reproducibility of the measurements should not be ensured to the detriment of the ability of the methods to discriminate between different situations. For example, during a comparative study of 7 methods of evaluation of the slip resistance of surfaces, Tisserand et al. (1997) calculated the ratio of the interval of variation of the measurements carried out on the 14 surfaces studied to the repeatability index - repeatability being a less stringent criterion than the reproducibility -. In effect, they found that one measurement device turned out to be poorly adapted, even though it had the same level of repeatability as the others. The interval of measurements was too narrow to allow for a good level of discrimination between surfaces. 


\subsection{VALIDITY}

The notion of validity is more open to interpretations. Strandberg (1983) defined a valid method as one that provides pertinent measurements that are correlated with the real slip resistance during walking. In a more general manner, Skiba et al. (1986) defined a method as being valid if it really measures what it is supposed to measure. These definitions explain the occasionally divergent approaches encountered when estimating the validity of a method of measurement.

It should be recalled that the INRS ensured the validity of its method by verifying that the measurements of slip resistance were correlated with the impression of safety felt by the test subjects - a method that is often qualified as subjective evaluation -. Lanshammar and Strandberg (1985) developed another global method that they qualified as psycho-physical - eff $\$ / 4 /$. In these two reference methods the subjects are placed in a risk situation, and are asked to express safety-related to slipping in terms of their sensations or performances. Of course, it is not enough that a method rely upon subjects in order to serve as a reference for validity. And, in all cases, the method is only valid in terms of the situation studied (walking, curves, running). It is therefore interesting to consider a maximum number of experimental conditions in reference procedures.

Subjective evaluation is becoming more and more widely used ( e.g. Nagata, 1987 ; Harris and Shaw, 1988 ; Kuschefski, 1989 ; Gronqvist et al., 1993 ; Myung et al., 1993), probably because it is easy to implement. In fact, gathering impressions related to the feeling of safety in terms of a precise risk requires that certain precautions be taken. Effectively, sensations dealing with friction and slipping are rather poorly memorised. Furthermore, other characteristics such as comfort and aesthetic impressions can also disturb the subject's judgement. For this reason, the INRS chose to use a method based on 
paired comparison, that implicates several subjects who have received very precise instructions (Tisserand and Saulnier, 1987a and 1987b). This method also requires that noticeable differences exist between the situations to be tested in order that they can be subjectively evaluated. Such precautions are not necessary with the psycho-physical method of Lanshammar and Strandberg (1985) - ef $\$ 4$-. On the other hand, this last method requires a very awkward mechanical device.

It should also be noted that in seeking to increase the validity of a method can occasionally cause problems related to the reproducibility of the results. Recall that Gronqvist (1989) varied the shoe/surface angle during the measurements in order to better simulate a slip, which in turn led to an insufficient level of reproducibility.

\section{THE THEORETICAL MECHANISMS IN FRICTION}

The tribological phenomena that occur at the sliding shoe/surface interface are very complex. Certain authors have tried to analyse these phenomena in order to better understand, and better master the measurement of slip resistance and its variability. The friction force $\mathrm{T}$ at the interface between an elastomeric sole and a rigid surface during a sliding motion is the sum of several terms : $\mathrm{T}=\mathrm{T}_{\mathrm{a}}$ $+T_{h}+T_{\alpha}$. The term $T_{a}$ (adhesion) is the consequence of a succession of creations and ruptures of molecular bonds between the elastomer and the surface. The second component, $\mathrm{T}_{\mathrm{h}}$ (hysteresis), is due to the periodic deformation of the mass of elastomer sliding over the asperities or pattern of the surface coating (see figure 3 for these two components). The last term, $\mathrm{T}_{\alpha}$ is indicative of shape effects, for example the fact that the elastomer sole contains a ridge perpendicular to the direction of displacement. This last component is especially important in the case where a viscous liquid is present 
between the surface and the sole. Other components can also be included in the above expression, but their contribution with respect to the situation studied is usually negligible. These include the opposing force generated by the fluid located between the surface coating and the sole, and the cohesive force (Moore, 1972 ; Bonefeld, 1981).

The dynamics of the forces occuring during a slip (evolution of the driving force exerted by the person, slip speed,...), as well as the industrial situation in question (roughness of the surface, contaminants present on the surface, sole material,...) will determine $\mathrm{T}$, i.e. the relative importance of each of the components.

Numerous authors have examined to what extent theoretical models can be used to explain the friction at the interface between a contaminated surface and a sole while walking :

- As early as 1981 , Bonefeld presented in detail the tribological concepts that play a role in the analysis of slipping, and in particular a list of the principal factors that have an influence on the different components of the friction force. This list contains approximately 50 factors related to the floor surface, the sole, lubricants present between the sole and the surface, and the movement of the sole. This list was originally established by Kummer (1966), who concluded that it was impossible to enumerate the exact number of factors that influence the friction of a viscoelastic body.

- In 1985, Strandberg revealed 3 essential processes upon which the slip resistance at a sole/surface interface depends : the squeezing of the viscous film, hysteresis and adhesion. He explained how these processes intervene at the moment of impact of the heel. When the lubricant present on the surface has been displaced enough (film squeeze) to allow the sole to cover the asperities on the surface, the hysteretic properties of the sole (especially of the heel) become decisive in the slip. Adhesion is essential when molecular bonds can be established between the shoe and the surface. 
- Gronqvist (1995a) detailed the effects of the contact pressure on adhesion and hysteresis. He explained the astonishingly low and unstable values of friction occasionally observed for subjects moving on slippery surfaces, in terms of elasto-hydrodynamic phenomena and of boundary lubrication (the surface/elastomer contact exists in certain parts, and are separated by the liquid in others). In effect, Strandberg (1985) indicated that, during his experiments with test subjects, certain surface/shoe combinations (when the contact surface seem to vary significantly between steps) are more disappointing than others even if they show the same average friction index.

- In 1987, the INRS acquired a Portable Friction Tester developed by the VTI (National Institute for research on circulation and roads in Sweden) for the measurement of the slip resistance of floor surfaces. This device measures a friction index between a braked wheel covered by a smooth elastomer and the surface. The model of the squeeze of the liquid film used by Strandberg (1985) is well-adapted to the principle of this measurement (cf. Leclercq et al., 1993). Numerous measurements were made at the INRS with this portable device in different conditions. Since the elastomer covering the test wheel is smooth, only the hysteretic and adhesive components are significant. The relative importance taken on by each of these components of the friction force as a function of the composition of the elastomer on the test wheel, its state of wear, the viscosity and quantity of lubricant (on the surface), and the state of the floor coating allows one to interpret the measurement differences recorded with this device (Leclercq et al., 1995b).

- Wieder (1986) explained how the deformation of the different parts of the pattern of the relief on the sole of the shoe contributes to the overall friction.

- Proctor and Coleman (1988) compared several methods of assessment of a friction index in terms of the theory of the "hydrodynamic" squeeze of the liquid film since most of these measurement techniques are based on the evaluation of the slip resistance of a test strip sliding over a floor surface. 
These methods do not integrate the phenomenon of vertical squeeze (qualified as hydrostatic by Proctor and Coleman (1988), and modelled by Strandberg (1985)). According to Gronqvist (1995a), neither of the 2 simplified models used by Strandberg (1985) or Proctor and Coleman (1988) is sufficiently accurate to represent real situations. In order to be able to do so, only a complete model of film squeezed based on Reynolds equation, which takes the characteristics of the movement of the foot in both directions, is said to be well-adapted.

\section{SAFETY THRESHOLD}

The safety threshold can be defined as a limit below which the risk of slipping and falling is sufficiently low. Even though the association of a single index, or of a combination of indices with a shoe or floor coating is an oversimplification, no concrete proposition of several criteria is to be found in the literature. In fact, only one single threshold value is ever proposed.

The work done on the dynamics of the forces exerted during walking on a slippery surface led Strandberg and Lanshammar (1981) to propose a safety threshold of 0.20 - even though they point out that this limit depends on walking characteristics -. Essentially, these authors observed that the risk of falling during normal walking was highest at the instant of impact of the heel, and that the (used) friction varied over the range of 0.1-0.2 in the case where the foot slid forward but did not lead to a fall. Consequently 0.2 is the value chosen by Gronqvist (1989) for his method that employs a device that simulates a slip at the instant of the impact of the heel. Stevenson (1992) proposed a value of 0.4 . Other safety thresholds have been proposed in the literature (see for example Miller, 1983 ; Gronqvist, 1989 ; Bönig, 1996). Certain safety thresholds have been proposed more by mutual consensus than 
in terms of scientific evidence. This is the case, for example, of the threshold of 0.5 for the index of static friction adopted in the U.S.A. (e.g. Redfern and Bidanda (1994)). This is what is (in a certain way) recommended in some cases by Skiba (1988). This author said that since the extent of technical understanding was insufficient to allow us to reach a safety limit for shoes and surface coatings, then it is preferable to adopt a lower value for a technical recommendation. In order to develop its own method for the evaluation of slip resistance, the INRS sought a criterion that was correlated with the impression of safety, and that was not really oriented toward the modelling of the slip phenomenon, even if biomechanical measurements were necessary in order to determine the order of magnitude of the measurement parameters. In this case, a threshold value of 0.15 , defined from a series of measurements carried out on a set of products, seems to be more of a technical recommendation than a safety threshold (Tisserand, 1985).

\section{STANDARDS}

The selection of safe products (shoes, floor coatings) implies that one is able to choose a measurement technique and safety threshold - a procedure that could be standardised. Standards on the evaluation of the slip resistance of surfaces and shoes do exist (e.g. Stevenson, 1992 ; Lara and Masounnave, 1993 ; Myung et al., 1993 ; Tisserand et al., 1997). Some of these were developed without paying attention to the concept of validation (see Leamon (1992) who discusses this subject), and others indicate a regulatory limit for a friction index without details on the relevant measurement technique (e.g. English, 1992 ; Stevenson, 1992). It is not particularly useful to list these standards here since the principal objective of this section is to discuss the major difficulties 
that seem to be encountered by the current Standardisation Committees from the point of view of the accident prevention specialist.

Following the inter-laboratory project for the comparison of measurement devices directed by Strandberg (NBOSH), it was possible to formulate a number of requirements for the evaluation of slip resistance. Strandberg (1983a) demonstrated that none of the existing methods or devices was unanimously chosen and that a universal procedure appeared to be a utopia if we consider the large number of requirements that must be satisfied in the following covering areas (this list is not exhaustive) :

- from tests in the laboratory to field tests,

- from an overall assessment of a surface coating to the optimisation of a sole,

- from a highly localised measurement to a measurement made over a large area,

- from an average index to a measurement of temporal variation,

- from testing a new product to testing a product that has undergone artificial wear,

- from tests on a safety shoe to tests on a street shoe.

In 1985, Hoang et al. expressed the same sort of scepticism toward the definition of an international standard in the near future. James (1980) understood the need to associate a surface or shoe with a single index. Nevertheless, this same author underlines the fact that work done in this area show that a single index cannot reflect the behaviour of a pair of materials.

It would seem that the basic difficulty for researchers is to give up trying to transcribe all of the results of their research - research which, because of their progress, has led to a better understanding of the complexity of slips - into a standard. A standard should rely on well established results that are recognised by everybody. However, we saw above that there is a lack of consensus, especially in terms of a methodology for the validation of a measurement method. The individual approaches used to define existing measurement 
methods and devices are all justified and supported. It is likely that a good number of them could even be incorporated into a standard. However, it still remains that they must be accepted by all. In addition to the difficulty of reaching a consensus in the scientific community, one must also consider the commercial implications to manufacturers. Even though validity is probably the primary concern of the scientific researcher, reproducibility and simplicity are surely priorities for manufacturers. Furthermore, the manufacturers will probably also prefer a method that has already been standardised.

Let us take for example the previous French Standard (AFNOR NFS 73.010, 1984) on safety shoes and boots. This standard covered the slip resistance of smooth, greasy industrial flooring, a specification applicable to certain types of safety boots and shoes. In 1987, Tisserand and Saulnier (1987a) observed during a measurement campaign that the products present on the market at that time presented a better slip resistance than products that had been tested in 1978. The standard thus pushed safety shoe and boot manufacturers to improve the slip resistance of their products. European standards that replaced the general standard cited above do not contain the specification related to the slip resistance of safety footwear. While waiting for a European standard in this area, the experimental French Standard (AFNOR XPS 73.012, 1995) contains the exact recommendations in terms of the test method included in the previous standard (AFNOR NFS 73.010, 1984). This example concerns safety shoes. Floorings is another area of standardisation currently debated. From a scientific point of view, a universal standardised test method is the ultimate goal for measuring the slip resistance of all kinds of floorings and footwear.

In the event that a valid, reproducible method can be proposed, a standard constitutes an important step toward safer products, even if it is not the only possible solution for the prevention of slipping.

Once a valid, reproducible method has been universally accepted, the choice of a threshold or technical recommendation in terms of safety should be relatively 
easy to make. If the procedure does not specify a particular device, it should be possible to calculate an adjustment of scale for every test machine, as specified by Jung and Fischer (1993b).

\section{RECOMMENDATIONS}

Having a method for the evaluation of slip resistance will allow one to :

- compare products (surfaces, shoes) to each other from the point of view of their slip resistance (e.g. Tisserand and Saulnier, 1987a ; Jung, 1993),

- study the influence of the characteristics of surfaces (state of the surface, permeability, etc.) or shoes (nature, state of the surface, tread, etc.) on their slip resistance.

These studies lead to recommendations for slip prevention. They are carried out in a laboratory on a particular device. However, we have seen that the measurement of the slip resistance is sensitive to several parameters, including the dynamics of the movement of the foot relative to the surface, measurement parameters (apparent pressure, slip speed, etc.) and the environmental situation being simulated (ice, smooth greasy surface, shoe, etc). Also, the results must always be considered in terms of the particular context of the measurement. Only tendencies can be proposed, tendencies that can be confirmed or invalidated by other work should be proposed. The goal of this paragraph is to provide an overview of the results of this type of experimentation and the recommendations that they lead to, and, whenever possible, to detail the possible limitations of the application. 


\subsection{ANTI-SLIP SHOE OR FLOOR ?}

In most cases, the increased friction provided by a modification of the floor covering is higher than that obtained by modifying the sole of the shoe (e.g. Wieder, 1986 ; Gronqvist et al., 1992).

\subsection{CLASSIFICATION OF SHOES ACCORDING TO THEIR SLIP RESISTANCE}

Wilson and Perkins (1985) ; Gronqvist and Hirvonen (1992) as well as Leclercq et al. (1995a) all observed that the classification of footwear in terms of their slip resistance was different as a function of the test surface used. Leclercq et al. looked at oiled surfaces, Gronqvist and Hirvonen considered dry and wet ice. On the other hand, Manning et al. (1991) obtained a classification of shoes (already worn in an oily environment) that was in agreement on all of the test surfaces considered : floor covered with oil or water, dry and wet ice. This result was confirmed by Manning and Jones (1995) for new shoes.

Two explanations for this have been offered :

- the difference in the methods used to measure slip resistance by the different laboratories.

- the difference between icy surfaces (when the surfaces are of this type).

\subsection{VARIATION OF THE SLIP RESISTANCE OF THE SOLES OF THE} SHOE

The slip resistance of shoes is a transient quality. Mechanical and chemical aggressions to the sole, which are specific to the context in which the shoes are used, can modify its slip resistance. Experimental results tend to show that the slip resistance of a shoe increases very rapidly as soon as it is worn (Wragge 
and Jung, 1986 ; Gronqvist et al., 1988 ; Jung, 1991 ; Stevenson, 1992 ; Leclercq et al., 1995a). According to Gronqvist et al. (1988) and Stevenson (1992), it would seem that the slip resistance then diminishes as soon as the tread of the sole disappears. It is for this reason that an artificial abrasion of the sole before assessment of the slip resistance, preferably systematically before sale is proposed in the literature (Manning et al., 1985 ; Gronqvist et al., 1988 ; Stevenson, 1992 ; Manning and Jones, 1994 ; Gronqvist, 1995b ; Jones et al., 1995). Gronqvist (1995b) even recommended the installation of abrasive mats so that the soles could be roughened up from time to time.

Slip resistance is also a versatile quality. Leclercq et al. (1995a) observed that the slip resistance is not identical for all of the new shoes of the same model. Different manufacturing and storage conditions could explain this variation, including, for example, a modification of the composition of the elastomer in the sole in order to improve other properties of the shoe, er a variation in the conditions of fabrication to diminish costs, or even wear and tear on the mould. Skiba (1985) underlined the fact that the composition of the sole and the manufacturing process certainly has an influence on slip resistance. Such mechanisms are not explored in detail.

\subsection{NATURE OF THE ELASTOMER FROM WHICH THE SOLE IS} MADE

Here again, the results are contradictory. However, slightly worn microcellular polyurethane is generally preferred. It should be pointed out that, when new, this sole material does not provide a very high level of slip resistance.

Skiba (1985) observed that NBR gives a better slip resistance than PVC, which in turn does better than microcellular PU. Leclercq et al. (1995a) measured lower value of slip resistance on smooth, oiled surfaces in the case of (new) soles of microcellular PU than for soles made from compact elastomers. On the 
other hand, the slip resistance of the latter sole materials did not increase nearly as much as that of the PU just after they had begun to be used. Gronqvist (1995b) recommended the use of slightly "worn" soles of microcellular PU on smooth, contaminated surfaces, and the use of TR on dry, icy surfaces. These results contradict those of Bruce et al. (1986), who recommended the use of microcellular PU on oily surfaces and dry ice, with PVC being the most slippery material. In fact, Manning et al. (1991) pointed out the difficulty of measuring friction indices on ice, first of all because the friction index is so low, and secondly because the surface of ice is highly irregular. Gronqvist and Hirvonen (1995) claimed that ice is smoother and cleaner in the laboratory than on-site, and that wetted ice is at least four times more slippery than dry ice. Manning and Jones (1994) proposed the PU T66/103 as being the best adapted product for use on wet or oily surfaces.

\subsection{HARDNESS OF THE ELASTOMER FROM WHICH THE SOLE IS} MADE

Skiba (1985) observed that the slip resistance increased on dry surfaces as the hardness of the sole diminished. Gronqvist (1995b) recommended that soft materials (Shore $A<60$ ) be used on smooth surfaces and dry ice. Leclercq et al. (1995c) did not observe any influence of the hardness of the sole material on the slip resistance of safety shoes as measured on oiled stainless steel.

\subsection{ROUGHNESS AND TREAD OF THE SOLE.}

A compromise must be made between maximising the contact surface of the elastomer and the floor, and allowing for the evacuation of a liquid at the interface through the channels of the tread (Lloyd and Stevenson, 1989a). It has been recommended that micro-asperities, the instep and arch be eliminated 
(Tisserand, 1985 ; Gronqvist, 1995b), and that tread in the form of suction cups or a border around the exterior of the sole be avoided (Leclercq et al., 1995c). Gronqvist (1995b) recommended a minimum surface contact area of $10 \mathrm{~cm}^{2}$, a minimum tread depth of $1.5 \mathrm{~mm}$, and a minimum average roughness $(\mathrm{Ra})$ of the elastomer surface of $5 \mu \mathrm{m}$.

Given that during normal walking the critical moment in terms of the risk of slipping is the moment of impact of the heel on the ground, several authors have stressed the importance of the tread and anti-slip properties of this portion of the sole. These authors measured the slip resistance with the shoe at an angle of several degrees with respect to the ground, and recommended the use of a bevelled heel that eliminates the posterior edge of the sole and helps to increase the surface area at the instant contact is made (Lloyd et Stevenson, 1989a ; Gronqvist, 1995b). However, after modelling the phenomenon of the squeeze of the viscous film between the sole and the surface, Strandberg (1985) recommended a non-bevelled heel in order to generate a high pressure, and thus to establish contact between the elastomer and the surface more rapidly on contaminated surfaces. Here again, a compromise must be made.

\subsection{ROUGHNESS OF FLOOR COATINGS.}

There are a wide variety of surface states available for industrial floor coatings (smooth surfaces, rough surfaces, and those with geometric reliefs). These states can be modified by cleaning products, wear, and contamination. Until now, the measurement of roughness has essentially concerned smooth, or not particularly rough surfaces. Very often, only a single dimensional index measured for a geometric profile is used : Ra, the average roughness index, or $\mathrm{Rtm}$, a function of the peak-trough differences. These limits are imposed by the devices used to measure roughness, which often can only be used to obtain an 
estimate of one feature of the state of the "smooth" surface (Lloyd and Stevenson, 1992 ; Gronqvist, 1995b).

Several authors have proposed a threshold value for a given roughness index that depends on the contaminant present on the surface (see Table 1) :

- Harris and Shaw (1988) and Proctor (1993) used an analysis of friction measurements done in the presence of water to propose that floor surfaces should have a minimum Rtm value of $8-10 \mu \mathrm{m}$ and $5 \mu \mathrm{m}$ respectively. Proctor explained the difference between the two thresholds by the fact that the elastomer that he used in the measurements was harder and had no tread with respect to that used by Harris and Shaw.

- Wieder (1988) proposed that, in the presence of water, surfaces should have a minimum value of $\mathrm{Ra}=8 \mu \mathrm{m}$, and $\mathrm{Ra} \cong 35 \mu \mathrm{m}$ in the presence of oil.

- Grönqvist (1995b) proposed that surfaces should have a minimum value of 7-9 $\mu \mathrm{m}$. When solid or viscous products are present, he recommended that surfaces with raised geometric patterns be installed, in combination with sufficient surface roughness ( $\mathrm{Ra}$ at least 7-9 $\mu \mathrm{m}$ ) and/or microporous floor surface.

- Lloyd and Stevenson (1992) looked for a model to reflect the state of the surface, and that takes the amplitude of the asperties ( $\mathrm{Ra})$, their sharpness (Rq) and the form and wavelength of the roughness profile (Rsk and $\lambda q$ respectively) into account. $\mathrm{Ra}$ and $\mathrm{Rq}$ were dependant variables for all of the surface coatings studied. Consequently, in the event of the analysis of friction measurements carried out in the presence of oil, they proposed the two following optimal indices : Ra near $46 \mu \mathrm{m}$, Rsk equal to zero or positive and $\lambda \mathrm{q} \cong 0,9 \mathrm{~mm}$ 
- Based on in situ and laboratory measurements, Ballance et al. (1985) observed that the friction index increased at the same time as the number and sharpness of the surface asperties.

- Wragge and Jung (1986) specifically studied slip on board ships. They showed that the anti-slip properties of deck paints were not improved if the size of the particles added to the paints was not big enough. They found similar results for the raised patterns on the deck surfaces.

\subsection{PERMEABILITY OF SURFACE COATINGS}

Permeable contaminated surfaces offer better slip resistance than impermeable contaminated surfaces (Leclercq et al., 1997). Gronqvist (1995b) recommended the use of permeable surface coatings even if the value of $\mathrm{Ra}$ is between 2 and $6 \mu \mathrm{m}$.

\subsection{CHEMICAL ANTI-SLIP TREATMENT OF THE COATINGS OF SMOOTH SURFACES}

Gronqvist (1995b) observed that chemical anti-slip treatments helped to increase the level of slip resistance. Nevertheless, the effect of the treatment essentially depended on the contaminant present on the surface. The measured roughness characteristics of the surface were not necessarily affected by this treatment. No studies have been carried out on the consequences of this treatment on the mechanical resistance or permeability (of the surface).

\subsection{MAINTENANCE OF SURFACE COATINGS}

Most studies are on plastic surface coatings or wooden surfaces, and show that once waxes are dried, they do not appreciably decrease the slip resistance. 
When covered with water, surfaces layered with polish substances are significantly more slippery than those that are not.

- Ballance et al. (1985) observed that applying wax on wooden surfaces led to a decrease in the slip resistance that increased as the wax dried, and again after it was polished.

- Lloyd and Stevenson (1989b) observed that the slip resistance of waxed surfaces increased when the amount of wax applied decrease and/or when the waxes are less hard. They also showed that surfaces covered with polish substances have a lower slip resistance in the presence of water.

- Schröder et al. (1989) observed that, in general, cleaning products increase the slip resistance of a surface (up to 50\%), but that in the presence of water, the slip resistance can decrease with respect to that of a dry situation, particularly in the case of wooden surfaces (up to 80\%). The slip resistance of a treated, dampened coating is less than the slip resistance of a non-treated, dampened floor covering. The slip resistance of a treated surface probably depends on the state of the protective film, its hardness, and its thickness.

- Malkin and Harrison (1980) carried out measurements of the slip resistance on dry and wet ceramic tiles. They noted two types of deposit on this type of tile that decreased the slip resistance : organic deposits (grease) that can be removed through the use of solvents and alkaline detergents, or by light abrasion ; and inorganic deposits that are most frequently produced when there is an inadequate amount of rinsing after washing. These authors cite deposits of calcites that must be removed with acid, or silica deposits that are produced by detergents, and also the formation of silica-based materials (e.g. the reaction of a highly alkaline detergent with the ceramic material). This last phenomenon was observed by Harrison and Malkin (1983). According to them, repetition of this reaction over a long period of time can be irreversible, and the problems that take place on ceramic surfaces can also take place on concrete and a 
number of plastic floor coverings. They underline the importance of rinsing with clean water.

- After analysing about 600 measurements of slip resistance taken on industrial surfaces in situ, Leclercq et al. (1997) observed that :

- cleaning a surface does not automatically lead to an increase in its slip resistance : floor surfaces impregnated with oil (in certain mechanical milling operations) were even more slippery just after washing.

- the state of the surface was modified on a microscopic level by "fouling". This fouling is similar to the invisible phenomena analysed by Wildbrett and Sauerer (1992), who demonstrated that after cleaning for a usual period steel tubes that had been exposed to milk, the surfaces always contained residual contaminants (grease and/or protein films) that accumulated over a series of cleaning periods, and then tended toward a constant value. These phenomena probably depended on the hydrophobic or hydrophilic nature of the surfaces.

\subsection{CONCLUSION}

Recommendations on the soles of safety shoes and on the floor coatings deal with a large number of characteristics or properties of these products. Furthermore, the possible interaction of these different factors are not taken into consideration. Such interaction could be appreciable. For example, the effects on the slip resistance of the tread and material of the sole of a shoe are certainly not independent since the deformation of the raised patterns of the tread contributes to this resistance.

Research into the slip-related safety through the examination of anti-slip shoes or floor coatings occasionally leads to difficult compromises :

- do anti-slip shoes become very quickly worn out? 
- in the food industry, the roughness of the surface of the industrial floor coatings must also satisfy of ten contradictory safety and hygiene requirements.

- in so far as the permeability of the surface is concerned, the compromise is between the slip resistance and the absence of contaminants on the undercoatings due to the migration of oil, for example in certain mechanical milling operations.

\section{CONCLUSION}

2 major points should be stressed at the end of this discussion :

- The evolution of research into the prevention of same level falls. Until the beginning of the 1990s, work on the prevention of same level falls concentrated essentially on slipping, and dealt with methods of measuring slip resistance :

- statistical studies revealed the most critical environmental conditions (smooth, contaminated surface) and the activity most frequently encountered at the time of slipping (normal walk).

- biomechanical studies established the moments of the cycle during which slipping can occur under normal walking conditions, and provided an image of the surfaces in contact and the dynamics of the forces at the interface at these instants.

Thés information $\$$ west used in whole, or in part in different laboratories that specialise in this subject in order to define methods for the measurement of slip resistance. The biomechanical studies on slipping that were performed in the laboratory revealed a high level of intra- and inter-subject variability in the data recorded at the shoe/surface interface (ef 5 ). This variability constitutes one of the biggest obstacles to progress in this area. Even if the inter-subject variability can be explained in part by anthropometric differences, the overall 
variability is probably linked to different psycho-motor strategies used by the subject to confront the risk of falling or to cope with the loss of balance. More recent studies have thus been undertaken on these strategies. These studies were more generally concerned with the loss of balance and thus all types of same level falls. They did not concentrate only on the event that triggered the accident, but rather took into consideration a wider succession of events taking place before and after loss of balance. An overview of these studies on the prevention of falling accidents from a point of view of perturbed locomotion and posture is presented by Leclercq (1998b).

- The difficulty of harmonising methods for the measurement of slip resistance. Each specialised laboratory that is equipped with a method for the measurement of slip resistance generally pursues two distinct objectives :

- the use of their method to be able to produce the previously cited recommendations. Since the methods in use are not identical, the results are occasionally contradictory from a laboratory to the next.

- the harmonisation of measurement techniques at European and International levels.

A great deal of progress has been made in the area of slip prevention during the past ten years in the pursuit of the first objective. Despite a large number of comparative studies and standardisation work, there is still no consensus on a particular measurement technique at the current time. This literature review has allowed us to partially explain the reasons that slow down progress in this area : the reference chosen to decide whether or not measurements are valid is not always a global method even though Strandberg has shown that this is necessary. Furthermore, the question that Strandberg's work implicitly evokes (ef $\S 4.4)$ should be asked : "Is it necessary that measurement devices reproduce the events that occur at the moment that the heel enters in contact with the ground, or is it sufficient to show that the validity of the methods be 
demonstrated by comparison with a global reference method?". Perhaps the current objections to a given method, judged to be too simple or too precisely defined, objections fuelled by a desire to model the contact of the heel and by the variability of the dynamics of the forces at the interface at the moment of impact might disappear. After all, simplicity and precision are needed if the measurements are to be reproducible, and these qualities are not incompatible with the concept of validity via comparison with a global reference method.

\section{REFERENCES}

AFNOR NFS 73.010, 1984. Bottes et chaussures de sécurité. Spécifications et essais. AFNOR, Paris-la-Défense.

AFNOR XP S 73.012, 1995. Bottes et chaussures de sécurité. Résistance au glissement sur sols industriels lisses et gras. AFNOR, Paris -La Défense.

ANDRES, R.O. and CHAFFIN, D.B., 1985. Ergonomic analysis of slip resistance measurement devices. Ergonomics, 28(7) : 1065-1079.

BALLANCE, P.E. ; MORGAN, J. ; SENIOR D., 1985. Operational experience with a portable friction testing device in university buildings. Ergonomics, 28(7) : 1043-1054.

BLOSWICK, D.S. and LOVE, A.C., 1991. Slip potential during load carrying activities. Slipping, tripping and falling accidents conference, London.

BONEFELD, X., 1981. Die Bestimmung des Gleitverhaltens von Schuhsohlen auf Bodenbelägen. Forschungsbericht $\mathrm{Nr}$ 265, Dortmund, Bundesanstalt für Arbeitsschutz. 
BÖNIG, S., 1996. Experimentelle Untersuchung zur Festlegung von normgerechten Reibzahlgrenzwerten für gleitsicheres Gehen. Dissertation Vom Fachbereich Sicherheitstechnik der Bergischen Universität Gesamthochschule Wuppertal. Wuppertal, RFA.

BRING, C., 1964. Friction and Slipping. Bulletin 16 of the division of Building Construction, Royal Institute of Technology, Stockholm, Sweden.

BRING, C., 1982. Testing of slipperiness. Forces applied to the floor and movements of the foot in walking and in slipping on the heel. Document D5. Swedish Council for building research, Stockholm, Sweden.

BROUGH, R. ; MALKIN, F. and HARRISON, R., 1979. Measurement of the coefficient of friction of floors.J. Phys. D : Appl. Phys., 12 : 517-528.

BRUCE, M. ; JONES, C. and MANNING, D.P., 1986. Slip-resistance on icy surfaces of shoes, crampons and chains. A new machine. Journal of Occupational Accidents, $7: 273-283$.

CHAFFIN, D.B. ; WOLDSTAD, J. C. and TRUJILLO, A., 1992. Floor/Shoe Slip Resistance measurement. American Industrial Hygiene Association Journal, 53(5) : 283-289.

EKKEBUS, C.F. AND KILLEY, W., 1973. Measurement of safe walkway surfaces. Soap, Cosmetics, Chemical Specialties, février : 40-45.

ENGLISH, W., 1992. Progress Toward Valid Walkway Slip-Resistance Standards. The 6th Southeastern Safety and Health Conference and EXhibition, Atlanta, Georgia. 
GRONQVIST, R., 1989. An apparatus and a method for determining the slip resistance of shoes and floors by simulation of human foot motions. Ergonomics, 32(8) : 979-995.

GRONQVIST, R., 1995a. Mechanisms of friction and assessment of slip resistance of new and used footwear soles on contaminated floors. Ergonomics, $38(2): 224-241$.

GRONQVIST, R., 1995b. A dynamic method for assessing pedestrian slip resistance. Thesis for the degree of doctor of technology.

GRONQVIST, R. ; ROINE, J. and KORHONEN, E., 1988. Slip resistance of new and used safety shoes. Työ ja ihminen Z : 193.

GRONQVIST, R. ; HIRVONEN, M. and SKYTTÄ, E., 1992. Countermeasures against Floor Slipperiness in the Food Industry. Advances in Industrial Ergonomics and Safety IV, edited by S. Kumar, Taylor and Francis, London : 989-996.

GRONQVIST, R. and ROINE, J., 1993. Serious occupationnal accidents caused by slipping. Advances in Industrial Ergonomics and Safety V, edited by R. Nielsen and K. Jorgensen, Taylor and Francis, London : 515-519.

GRONQVIST, R. ; HIRVONEN, M. and TUUSA, A., 1993. Slipperiness of the shoe-floor interface comparison of objective and subjective assessments. Applied Ergonomics, 24(4) : 258-262. 
GRONQVIST, R. ; HIRVONEN, M., 1992. Slip resistance of winter shoes on icy surfaces. Proceedings of the Fourth Scandinavian Symposium on Protective Clothing Against Chemicals and Other Health Hazards, ed. by H. Mäkinen, Finland. 123-129.

GRONQVIST, R. ; HIRVONEN, M., 1995. Slipperiness of footwear and mechanisms of walking friction on icy surfaces. International Journal of Industrial Ergonomics, 16(3) : 191-200.

HARRIS, G.W. and SHAW, S.R., 1988. Slip resistance of floors : users'opinions, Tortus instrument readings and roughness measurement. Journal of Occupational Accidents, 9 : 287-298.

HARRISON, R. and MALKIN, F., 1983. On-Site testing of shoe and floor combinations. Ergonomics, 26(1) : 101-108.

HOANG, K. ; STEVENSON, M. G. and WILlgOSS, R. A., 1985. Measurement of dynamic friction between shoe soles and walkway surfaces. Proceedings of the 22nd Annual Conference of the Ergonomics Society of ANZ, Toowoomba, Australie, 265-271.

HOANG, K. ; STEVENSON, M. G. ; NHIEU, J. and BUNTERNGCHIT, Y., 1987. Dynamic Friction at Heel Strike between a range of protective Footwear and non-slip Floor surfaces. Report CSS/1/87. Published by the Centre for safety Science, Kensington, Australia.

JAMES, D. I., 1980. A broader look at pedestrian friction. Rubber Chemistry and Technology, $3: 512-541$. 
JAMES, D.I., 1983. The importance of kinetic friction. Ergonomics, 26(1) : 83-99.

JONES, C. ; MANNING, D.P. and BRUCE, M., 1995. Detecting and Eliminating slippery footwear. Ergonomics, 38(2) : 242-249.

JUNG, K., 1991. Änderung der rutschhemmenden Eigenschaften von Schutzschuhen während des Tragens. Zentralblatt für Arbeitsmedizin, Arbeitsschutz prophylaxe und Ergonomie, 41 : 38-44.

JUNG, K., 1993. Rutschhemmende Gitter-und Blechprofilroste zum Einsatz als selbsttragender Bodenbelag für hochgelegene Arbeitsplätze und Verkehrswege. Die BG, RFA, 5 : 311-316.

JUNG, K. and SCHENK, H., 1990. An international comparison of test methods for determining the slip resistance of shoes. Journal of occupational Accidents, $13: 271-290$.

JUNG, K. and FISHER, A., 1993a. Methods for checking the validity of technical test procedures for the assessment of slip resistance of footwear. Safety Science, $16: 189-206$.

JUNG, K. and FISHER, A., 1993b. An ISO test method for determining slip resistance of footwear. Determination of its precision. Safety Science, $16: 115-$ 127.

KUMMER, W., 1966. Unified Theory of Rubber and Tire friction. Engineering Research Bulletin B - 94, Pennsylvania State University. 
KUSCHEFSKI, A., 1989. Zur Validät von Reibzahlen als Bewertungskriterienn der Gleitsicherheit. Kautschuk-Gummi-Kunststoffe, 42(11): 1000-1002.

LANSHAMMAR, H. and STRANDBERG, L., 1985. Assessment of friction by speed measurement during walking in a closed path. Biomechanics, IX-B, eds D. Winter, R. Norman, R. Wells, K. Hayes, A. Patla (Human Kinetics Publishers, Champaign), 72-75.

LARA, J. ; MASOUNNAVE, J., 1993. Les chutes par glissade : révision des méthodes d'essai pour évaluer la résistance à la glissade. Communication personnelle. IRSST, Québec, Canada.

LEAMON, T.B., 1988. Experimental study of falling. Proceedings of the annual conference of the human factors Association of Canada, Edmonton, Canada, 157-159.

LEAMON, T.B., 1992. The Reduction of Slip and Fall Injuries : Part II - The scientific basis (knowledge base) for the guide. International Journal of Industrial Ergonomics, $10: 29-34$.

LECLERCQ, S., 1998a. In-company same and low level falls : from an understanding of such accidents to their prevention. To be published in the International Journal of Industrial Ergonomics.

LECLERCQ, S., 1998b. Prevention of same level falls : A more global appreciation of this type of accident. To be published in the Journal of Safety Research. 
LECLERCQ, S. ; TISSERAND, M. et SAULNIER, H., 1993. Quantification of the slip resistance of floor surfaces at industrial sites. Part II. Choice of optimal measurement conditions. Safety Science, $17: 41-55$.

LECLERCQ, S. ; TISSERAND, M. et SAULNIER, H., 1995a. Assessment of slipping resistance of footwear and floor surfaces. Influence of manufacture and utilization of the products. Ergonomics, 38(2) : 209-219.

LECLERCQ, S. ; TISSERAND, M. et SAULNIER, H., 1995b. Tribological concepts involved in slipping accident analysis. Ergonomics, 38(2) : 197-208.

LECLERCQ, S. ; TISSERAND, M. et SAULNIER, H., 1995c. Les chaussures antidérapantes. Application de l'expérimentation à la prévention. Cahiers de notes documentaires, $158: 47-55$.

LECLERCQ, S. ; TISSERAND, M. et SAULNIER, H., 1997. Analysis of the measurement of slip résistance of soiled surfaces on site. Applied Ergonomics, $28(4): 283-294$.

LLOYD, D.G. and STEVENSON, M.G., 1989a. Measurement of slip resistance of shoes on floor surfaces. Part 2 : Effect of a bevelled heel. Journal of Occupational health and safety - Australie NZ, 5(3) : 229-235.

LLOYD, D.G. and STEVENSON, M.G., 1989b. Measurement of slip resistance of shoes on floor surfaces. Part 3 : Influence of floor polishes on vinyl and terrazo floors. Journal of Occupational health and safety - Australie NZ, 5(4) : 301-306. 
LLOYD, D.G. and STEVENSON, M.G., 1992. An Investigation of Floor Surface Profile Characteristics that will reduce the Incidence of Slips and Falls. Transaction of Mechanical Engineering, ME 17(2) : 99-105.

MALKIN, F. and HARRISON, R., 1980. The Coefficient of Friction of Ceramic Tiles with relief surfaces. Interceram, 29(4) : 480-483.

MANNING, D.P. ; AYERS, I. ; JONES, C. ; BRUCE, M. And COHEN, K., 1988. The incidence of underfoot accidents during 1985 in a working population of 10000 Merseyside people. Journal of Occupational Accidents, 10 : 121-130.

MANNING, D.P. ; JONES, C. and BRUCE, M., 1990. Proof of Shoe Slip resistance by a walking Traction test. Journal of Occupational Accidents, 12 : 255-270.

MANNING, D.P. ; JONES, C. and BRUCE, M., 1985. Boots for oily surfaces. Ergonomics, 28(7) : 1011-1019.

MANNING, D.P. ; JONES, C. and BRUCE, M., 1991. A method of ranking the grip of industrial footwear on water wet, oily and icy surfaces. Safety Science, $14: 1-12$.

MANNING, D.P. and JONES, C., 1994. The superior slip-resistance of footwear compound T66/103. Safety Science, 18: 45-60.

MANNING, D.P. and JONES, C., 1995. High heels and polished floors : the ultimate challenge in research on slip-resistance. Safety Science, 19: 19-29. 
MILLER, J. M., 1983. Slippery work surfaces : towards a performance definition and quantitative coefficient of friction criteria. Journal of Safety Research, 14(4) : 145-158.

MOORE, D. F., 1972. Friction and Lubrication of Elastomers (Pergamon, Oxford)

MYUNG, R. ; SMITH, J. L. and LEAMON, T. B., 1992. Slip distance as an objective criterion to determine the dominant parameter between static and dynamic CoFs. Proceedings of the Human Factors Society, 36th annual meeting, 738-741.

MYUNG, R. ; SMITH, J. L. and LEAMON, T. B., 1993. Subjective assessment of floor slipperiness. International Journal of Industrial Ergonomics, $11: 313-319$.

NAGATA, H., 1987. The methodology of insuring the validity of a slip resistance meter. ISO TC 94/SC 3 WG 1 (Slip resistance meeting, France).

NF ISO 5725 , 1987. Application de la statistique. Fidélité des méthodes d'essais. Détermination de la répétabilité et de la reproductibilité d'une méthode d'essai normalisée par essais interlaboratoires. AFNOR, Paris la Défense.

PERKINS, P.J., 1978. Measurement of Slip between the Shoe and Ground during Walking. In :Walkway surfaces : Measurement of Slip Resistance, ASTM STP 649, Carl Anderson and John Senne, Eds., American Society for Testing and Materials : 71-87. 
PERKINS, P.J. and WILSON, M.P., 1983. Slip Resistance Testing of Shoes. New Developments. Ergonomics, 26(1) : 73-82.

PROCTOR, T. D., 1993. Slipping accidents in Great Britain - An update. Safety Science, $16: 367-377$.

PROCTOR, T. D. and COLEMAN,V., 1988. Slipping, Tripping and Falling accidents in Great Britain - Present and Future. Journal of occupationnal accidents, $9: 269-285$.

REDFERN, M. S. ; ANDRES, R.O., 1984. The analysis of dynamic pushing and pulling : required coefficients of friction. Proceedings of the 1984 International conference on occupationnal Ergonomics, Toronto, 569-572.

REDFERN, M. S. ; HOLBEIN, M.A. ; GOTTESMAN, D. and CHAFFIN, D.B., 1991. Kinematics of heelstrike walking and carrying : implications for slip resistance testing. Slipping, tripping and falling accidents conference, London.

REDFERN, M. S. and BIDANDA, B., 1994. Slip resistance of the shoe-floor interface under biomechanically relevant conditions. Ergonomics, 37(3) : 511524.

RHOADES, T.P. and MILLER, J.M., 1988. Measurement and comparaison of "required" versus "available" slip resistance. Proceedings of the Annual Conference of the Human Factors Association of Canada, 137-140. 
SCHRÖDER, H. ; HÜBNER, S. und SKIBA, R., 1989. Der Einfluss von Bodenpflegemitteln auf die Gleitsicherheit. Fett Wissenschaft Technologie, Allemagne, 91(5) : 193-199.

SKIBA, R., 1984. Geräte zur Bestimmung der Reibung zwischen Schuh und Fussboden unter Berücksichtigung des menschlichen Ganges. Kautschuk und Gummi-Kunststoffe, Allemagne de l'Ouest, 37(6) : 509-514.

SKIBA, R., 1985. Materialbedingte Gleitsicherheitseigenschaften von Schuhsohlen. Schuh-Technik +abc, $10: 894-900$.

SKIBA, R., 1986. Zur Ermittlung und Bewertung der Gleitsicherheit von Schuhsohlen auf Fussböden. Zentralblatt für Arbeitsmedizin, Allemagne, 36 : 68-73.

SKIBA, R., 1988. Sicherheitsgrenzwerte zur Vermeidung des Ausgleitens auf Fussbôden. Zeitschrift fûr Arbeitswissenschaft, Allemagne, 42 : 47-51.

SKIBA, R. ; BONEFELD, X. and MELLWIG, D., 1983. Voraussetzung Zur Bestimmung der Gleitsicherheit beim menschlichen Gang. Zeitschrift für Arbeitswissenschaft, 37S : 227-231.

SKIBA, R. ; WIEDER, R. und CZIUK, N., 1986. Zum Erkenntniswert von Reibzahlmessungen durch Begehen einer neigbaren Ebene. Kautschuk + Gummi, Kunststoffe 39. 10/86 : 907-911.

SKIBA, R. ; KUSCHEFSKI, A. und CZIUK, N., 1987. Entwicklung eines normgerechten Prüfverfahrens zur Ermittlung der Gleitsicherheit von 
Schuhsohlen. Schriftenreihe der Bundesanstalt für Arbeitsschutz, Fb 526 : 725.

SKIBA, R. ; SCHEIL, M. ; WINDHÖVEL, U., 1994. Vergleichsuntersuchung zur instationären Reibzahlmessung auf Fussböden. Kautschuk und Gummi Kunststoffe, 47(7) : 513-518.

SOAMES, R. W. and RICHARDSON, R. P. S., 1985. Stride length and Cadence : Their influence on ground reaction force during gait. Biomechanics IX-A ; eds Winter, Norman, Wells, 406-410.

STEVENSON, M. G., 1992. Proposed standard testing methods for slip resistance. Journal of occupational Health and Safety, Australia and New Zealand, 8 : 497-503.

STEVENSON, M. G. ; HOANG, K. ; BUNTERNGCHIT, Y. ; LLOYD, D., 1989. Measurement of slip resistance of shoes or floor surfaces. Part I : Methods. Journal of occupationnal Health and Safety, Australia NZ, 5(2) : 115120.

STRANDBERG, L., 1983a. Ergonomics applied to slipping accidents. In Ergonomics of Workstation Design edited by T.O. Kvalseth, university of Minnesota. Butterworths and Co., London.

STRANDBERG, 1983b. On accident analysis and slip resistance measurement. Ergonomics, 26(1): 11-32.

STRANDBERG, L., 1985. The effect of conditions underfoot on falling and overexertion accidents. Ergonomics, 28(1) : 131-147. 
STRANDBERG, L. And LANSHAMMAR, H., 1981. The dynamics of slipping accidents. Journal of Occupationnal Accidents, 3 : 153-162.

STRANDBERG, L. And LANSHAMMAR, H., 1985. Walking Slipperiness Compared to Data from Friction Meters. Biomechanics IX B, Eds. D. Winter, R. Norman, R. Wells, K. Hayes and A. Patla. Champaign : Human Kinetics Publishers, 76-81.

TISSERAND, M., 1969. Critères d'adhérence des semelles de sécurité, Rapport d'étude INRS.

TISSERAND, M., 1985. Progress in the prevention of falls caused by slipping. Ergonomics, 28(7) : 1027-1042.

TISSERAND, M. et SAULNIER, H., 1987a. Résistance des bottes au glissement. Bottes en élastomère utilisées dans les industries de l'alimentation. Travail et Sécurité, ED 1235.

TISSERAND, M. et SAULNIER, H., 1987b. Facteurs de conception determinant la glissance des chaussures. Technique Chaussure Maroquinerie, mai, $10-12 ; 20,21$.

TISSERAND, M. ; SAULNIER, H. and LECLERCQ, S., 1997. Comparison of seven methods for the evaluation of the slip resistance of floor coverings : Contributions to development of Standards. From Experience to Innovation, Proceedings of the 13th Triennal Congress of the International Ergonomics association, $3: 406-408$. 
TISSOT, C., 1994. Analyse des glissades figurant dans la base EPICEA. Communication personnelle.

WIEDER, R. M., 1986. Untersuchung ûber den Einfluss des Profils von Schutzschuhen auf die Gleitsicherheit beim Menschlichen Gang. SchuhTechnik + abc, Allemagne, octobre, 732-734.

WIEDER, R. M., 1988. Experimentelle untersuchungen über den Einfluss der Ober flächenrauheit auf die Gleitsicherheit beim Menschlichen Gang. Vom Fachbereich Sicherheitstechnik der Bergischen Universität Gesamthochschule Wuppertal zur Erlangung des akademischen Grades eines Doktor-Ingenieurs genehmigte Dissertation.

WILDBRETT, G. et SAUERER, V., 1992. Reinigungsverhalten von Edelstahl und Kunststoffrohren. SÖFW Journal, 118, Jahrgang, 15/92.

WILLIAMS, W.D. ; SMITH, J.A. and DRAUGELIS, F.J., 1972. TOPAKA : New device and method for measuring slip resistance of polished floors. Proceedings of the 58th mid-year meeting of waxes, polishes and floor finishes division. Published by Chemical Specialties Manufacturers Association, Inc., New York.

WILSON, M. P., 1991. Development of Satra Slip test and tread pattern design guidelines. Communication to the Slipping, Tripping and Falling Accidents Conference, Londres.

WILSON, M.P. and PERKINS, P.J., 1985. Evaluation of a slip resistance test for shoes. Ergonomics, 28(7) : 1081-1085. 
WRAGGE, F. und JUNG, K., 1986. Zur Frage der Gleitsicherheit und der eignung von schutzschuhwerk unter den bedingungen der Seeschiffahrt. Die B.G., R.F.A. : 566-571. 
Figure $1:$ Representation of the forces at the shoe/surface interface at time $t$. An individual walking on a surface applies in the contact zone between the sole and the surface a force $\overrightarrow{F_{M}}$, the amplitude and direction of which vary as a function of time. $\overrightarrow{F M}$ has 2 components : $\vec{T}$, which is situated in the plane of the surface, and $\vec{N}$, which is orthogonal to this plane. A reaction $\overrightarrow{F R}$ is opposed to this force, and its components $\vec{T}^{\prime}$ and $\vec{N}^{\prime}$ are opposed to $\vec{T}$ and $\vec{N}$ respectively. The force $\vec{T}$ tends to make the shoe slip on the surface, and the force $\vec{T}^{\prime}$ is the friction force that opposes this slipping. $\vec{T}$, in the plane of the surface is divided into two components : one in the direction of walking and one perpendicular to this direction. They have not been represented on this figure to keep it readable.

Figure 2 : Test bench for the evaluation of the slip resistance of safety shoes developed at the INRS

Figure 3 : Principal components of elastomeric friction (taken from Moore, 1972)

Table 1 : Roughness indices proposed for the state of the surface of floors. 


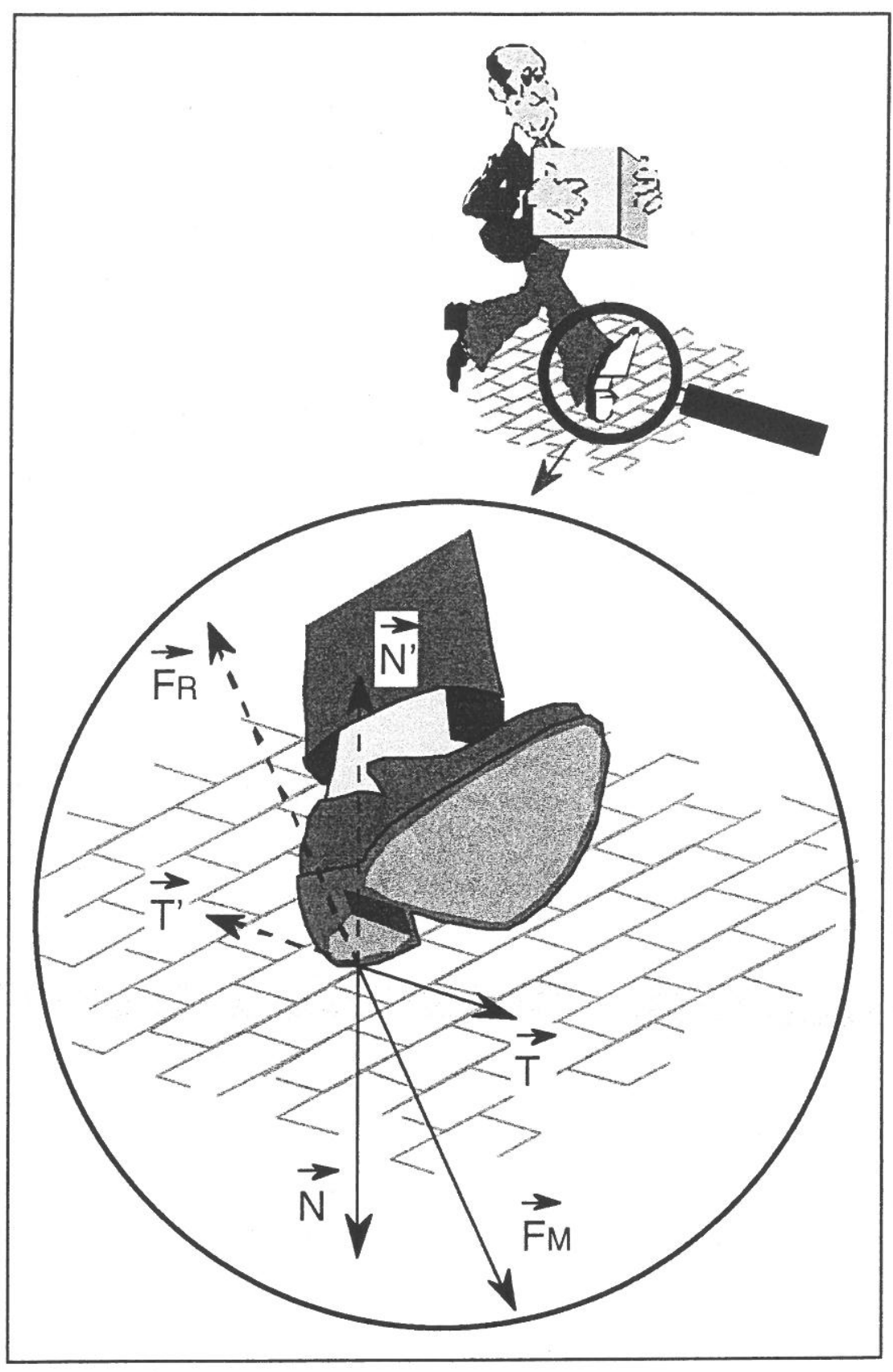

figure 1 


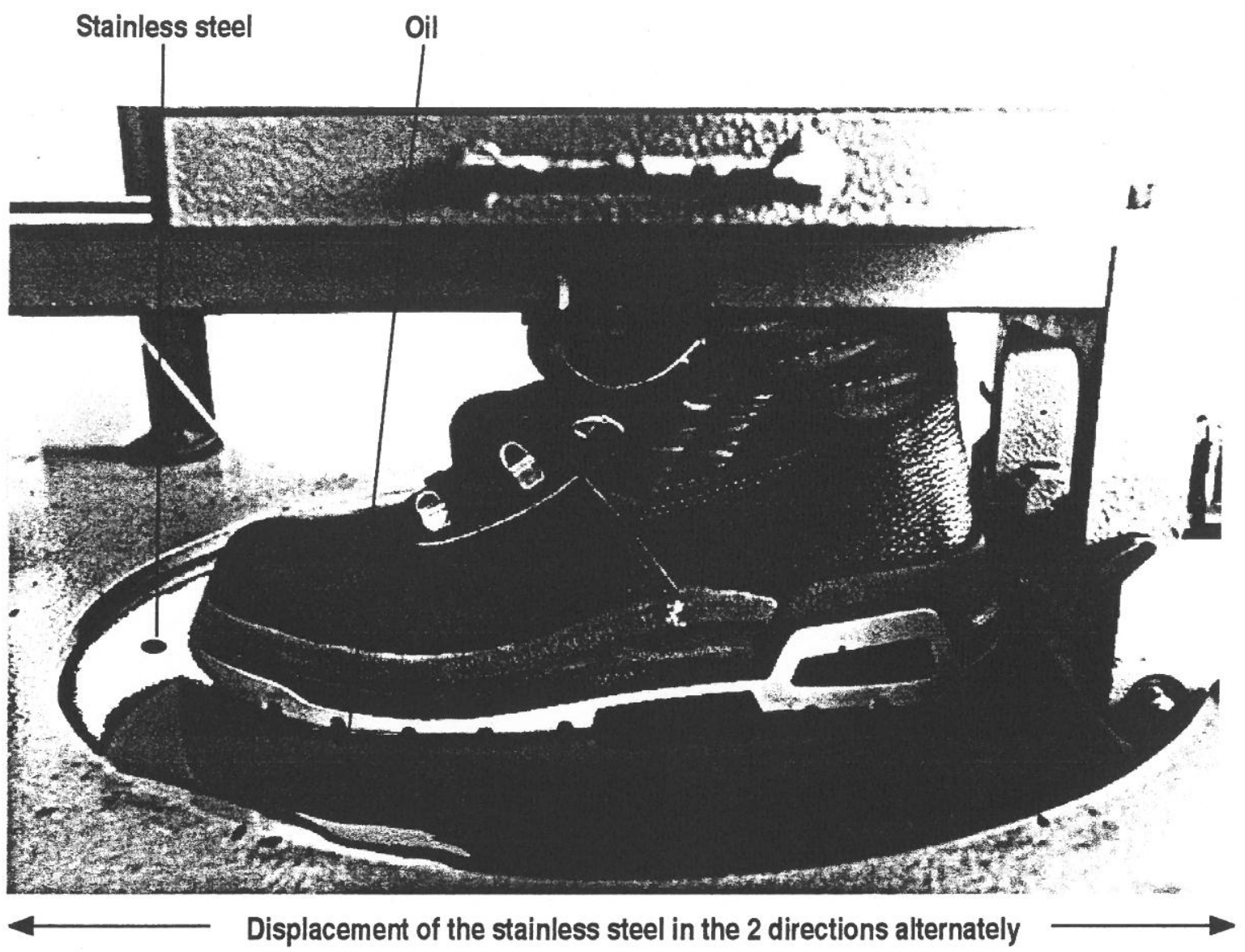

figure 2 


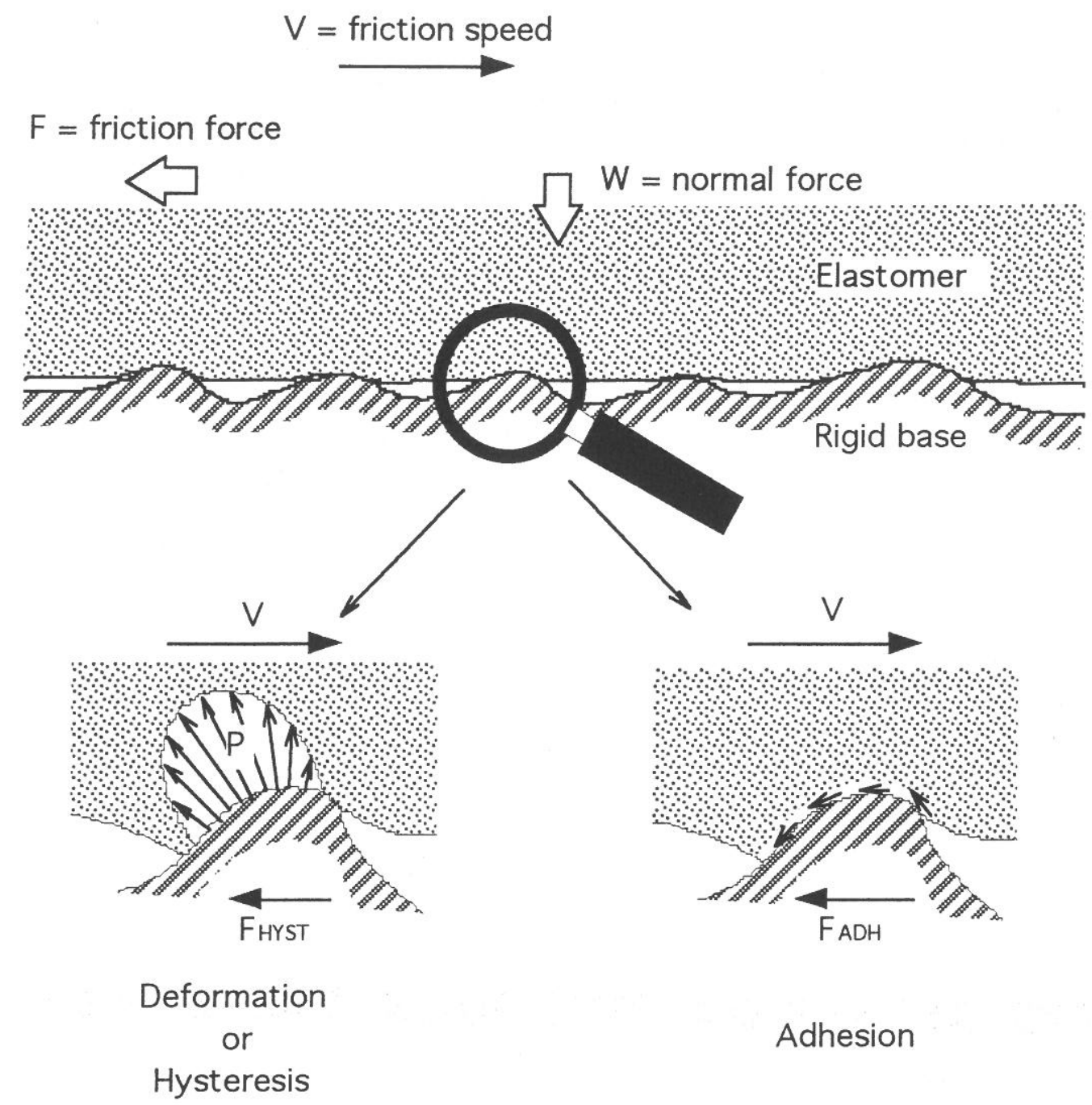

figure 3 


\begin{tabular}{|c|c|c|}
\hline Index of roughness & Water & Oil or viscous contaminant \\
\hline \multirow[t]{2}{*}{ Rtm } & $\begin{array}{l}\text { 8-10 } \mu \mathrm{m} \text { (Harris and Shaw, } \\
1988)\end{array}$ & \\
\hline & $5 \mu \mathrm{m}$ (Proctor, 1993) & \\
\hline \multirow[b]{2}{*}{$\mathrm{Ra}$} & $8 \mu \mathrm{m}$ (Wieder, 1988) & $35 \mu \mathrm{m}$ (Wieder, 1988) \\
\hline & 7-9 $\mu \mathrm{m}$ (Gronqvist, 1995b) & $\begin{array}{l}\text { 7-9 } \mu \mathrm{m} \text { plus geometric } \\
\text { patterns or large asperities } \\
\text { and/or microporous floor } \\
\text { surface (Gronqvist, 1995b) }\end{array}$ \\
\hline $\mathrm{Ra}$, Rsk and $\lambda \mathrm{q}$ & & $\begin{array}{l}\mathrm{Ra} \cong 46 \mu \mathrm{m}, \mathrm{Rsk} \geqq 0 \text { and } \\
\lambda \mathrm{q} \cong 0,9 \mathrm{~mm} \\
\text { (Lloyd and Stevenson, 1992) }\end{array}$ \\
\hline
\end{tabular}

table 1 